\title{
Growing inequities in maternal health in South Africa: a comparison of serial national household surveys
}

\author{
Njeri Wabiri ${ }^{1 *} \mathbb{D}$, Matthew Chersich², Olive Shisana ${ }^{3,4}$, Duane Blaauw $^{5}$, Helen Rees $^{2}$ and Ntabozuko Dwane ${ }^{1}$
}

\begin{abstract}
Background: Rates of maternal mortality and morbidity vary markedly, both between and within countries. Documenting these variations, in a very unequal society like South Africa, provides useful information to direct initiatives to improve services. The study describes inequalities over time in access to maternal health services in South Africa, and identifies differences in maternal health outcomes between population groups and across geographical areas.

Methods: Data were analysed from serial population-level household surveys that applied multistage-stratified sampling. Access to maternal health services and health outcomes in $2008(n=1121)$ were compared with those in $2012(n=1648)$. Differences between socio-economic quartiles were quantified using the relative (RII) and slope (SII) index of inequality, based on survey weights.

Results: High levels of inequalities were noted in most measures of service access in both 2008 and 2012. Inequalities between socio-economic quartiles worsened over time in antenatal clinic attendance, with overall coverage falling from 97.0 to $90.2 \%$. Nationally, skilled birth attendance remained about $95 \%$, with persistent high inequalities (SII =0.11, RII =1.12 in 2012). In 2012, having a doctor present at childbirth was higher than in 2008 (34.4\% versus $27.8 \%$ ), but inequalities worsened. Countrywide, levels of planned pregnancy declined from $44.6 \%$ in 2008 to $34.7 \%$ in 2012. The RII and SII rose over this period and in 2012, only $22.4 \%$ of the poorest quartile had a planned pregnancy. HIV testing increased substantially by 2012, though remains low in groups with a high HIV prevalence, such as women in rural formal areas, and from Gauteng and Mpumalanga provinces. Marked deficiencies in service access were noted in the Eastern Cape ad North West provinces.

Conclusions: Though some population-level improvements occurred in access to services, inequalities generally worsened. Low levels of planned pregnancy, antenatal clinic access and having a doctor present at childbirth among poor women are of most concern. Policy makers should carefully balance efforts to increase service access nationally, against the need for programs targeting underserved populations.
\end{abstract}

Keywords: Maternal health, South Africa, Equity gap, Access, National household survey, Relative inequalities

\section{Background}

South Africa is one of the most inequitable countries in the world, by almost any measure. The wealthiest 10 percent of the population, for example, accounts for more than half the country's income [1]. Indices of health, and especially of maternal health, clearly reflect the inequalities in access and health outcomes that mark

\footnotetext{
* Correspondence: nwabiri@hsrc.ac.za

${ }^{1}$ Epidemiology and Strategic Information Unit, Human Sciences Research

Council, Pretoria, South Africa

Full list of author information is available at the end of the article
}

the country. Maternal mortality varies considerably between provinces, for instance, with the institutional-level maternal mortality rates (MMR; maternal deaths per 100,000 live births) ranging from 69 in the Western Cape to 185 in the North West Province [2]. The prevalence of HIV also differs substantially between geographical areas. The 2012 national antenatal survey found that the HIV prevalence at district level ranges from 1.5 to $40.7 \%$, around a national average of $29.2 \%[3]$.

Maternal mortality has fluctuated over the past decades. Institutional MMR progressively escalated from the late 
1990s onwards, up to levels of 176 nationally in the 2008-2010 triennium, but dropped thereafter to 147 by 2012 [4, 5]. The wide scale-up of antiretroviral treatment (ART) across the country, and especially among pregnant women, is credited with these reductions $[5,6]$. While HIV-related mortality has decreased, maternal deaths due to haemorrhage have actually risen, especially among women who had a caesarean section [5]. The increase in these and other deaths from direct obstetric causes, are ascribed to deficiencies in the quality of maternal health services, most notably in patient transport, the availability of intensive care units and the provision of emergency obstetric care [5].

Health service data are available to guide improvements in the quality of services. The district monitoring systems have been strengthened [2] and the factors contributing to maternal deaths are frequently assessed $[4,6,7]$. What we lack, however, is an assessment of access to maternal health services at a population level, disaggregated by population group, and assessed over time. Analysing data from national household surveys can fill these gaps. A survey in 2008 [8] highlighted marked differences in maternal health status across socio-economic and other population groups, especially between rural and urban areas. Using data from a follow-up survey in 2012, the study presented here updates the 2008 findings and examines how inequalities have changed since then. The analysis focuses primarily on absolute and relative differentials between socio-economic groups, but also on the influence of factors such as rural-urban location, race and HIV status. More broadly, by determining the distribution and outcomes of maternal health services over time, the study identifies the underserved groups and geographical areas. This information can be used to help direct health system resources and initiatives to raise the quality of services.

\section{Methods}

\section{Survey sampling, field and laboratory procedures}

This paper is a sub-analysis of the third (2008) and fourth (2012) South African National HIV Prevalence, Incidence, Behaviour and Communication Surveys $[9,10]$. The two surveys employed multistage stratified sampling, taking into account province; locality (urban formal, urban informal, rural formal including commercial farms, and rural informal or tribal areas); and race groups. Full details of the survey methods, response rates and ethical procedures are detailed elsewhere $[9,11]$. In brief, the sampling frames were based on enumerator areas (EAs) used in the South Africa national census. The primary sampling units consisted of 1000 EAs, which were selected from a database of 86,000 EAs.
Fifteen households within each selected EA constituted the secondary sampling units $(15,000$ households). The same EAs were used in both surveys, but different households were selected. The final sampling unit was made up of eligible individuals within households. Anyone who slept in the household on the night preceding the survey (including visitors) was considered a household member. In 2008, only four persons were eligible to participate from each household; one in each age group $(0-1,2-11,12-14$, and above 15 years) [8]. In the 2012 survey, all persons in the selected households were eligible. Consenting participants responded to individual questionnaires. Dried blood spot specimens were collected from consenting participants, tested for HIV antibodies and linked anonymously with the questionnaires administered to study participants [12].

\section{Study variables and measures}

The analysis includes data collected from two groups of women aged 15-55 years: those who had been pregnant in the preceding 2 years and those interviewed as the parent or guardian of a child below two years. The study variables are described in the publication of the 2008 survey findings [8], and are only overviewed here. Socio-economic quartiles (SEQ) were derived from an asset score based on measures of household-living standards, and were generated using multiple correspondence analysis $[13,14]$. Quartiles were preferred over quintiles as the socioeconomic differentials are very narrow in many areas of the country, given that many women perform the same income-generation activities and thus have similar incomes and asset levels [8, 15]. Quintiles would thus have been unable to differentiate between women in Q1 and Q2, who have essentially the same living standards.

Access to maternal health services was measured by: utilisation of antenatal clinics; HIV testing coverage; and the presence of a skilled birth attendant (SBA) or doctor at birth [8]. Maternal health status was not assessed in detail within the survey, thus proxy indicators were used. Women who said they had a fair or poor health status were categorised as having a lower self-assessed health status, and compared with those reporting good or excellent health. Planned pregnancy, multiparity (five or more children), and prevalence of HIV infection were used as indicators of maternal health status, given their links with pregnancy outcomes for women and children [16].

Though the study focused on the distribution of access and outcomes by SEQ, variation was also assessed across other categories of social differentiation. The applicable categories of the PROGRESS-Plus acronym were used, namely: Place of Residence (province; 
locality as urban formal and informal, and rural formal and informal), Race, Occupation, Education, Socio-economic Status (SEQ and employment of the mother), and Age and HIV status representing the Plus category [17]. We also examined whether there were systematic differences in access to services between those with and without HIV infection.

\section{Statistical models and measures of inequality by socioeconomic status}

Data were analysed using Stata version 13.0 (College Station, Texas, United States [18]), taking into account the complex multilevel sampling design (by age, race group and province) and participant non-response. Summary indices for descriptive analysis are weighted percentages, while unweighted counts are provided. Clustering was not accounted for given that the large number of primary sampling units (1000) in the study is comparable to respondent number, diminishing such effects [8].

Socio-economic inequalities in maternal health were calculated using three inequality measures: the Slope Index of Inequality (SII) for quantifying absolute inequalities, and the Relative Index of Inequality (RII) and Concentration Index (CI) for assessing the magnitude of relative inequalities [19-21]. ArcGIS Desktop Version 10.0 was used to show the geographical variation in access to antenatal services and a skilled birth attendant, planned pregnancy and health status.

\section{Slope index of inequality and the relative index of inequality}

The SII and RII indices are regression based and take the whole wealth distribution into account, rather than only comparing the two most extreme groups (e.g., the wealthiest and poorest quartiles), such as done with a rate difference and rate ratio [20]. The RII and SII are "recommended when making comparisons over time or across populations" [22, 23]. While most trend studies focus on relative, as opposed to absolute inequalities [24], the use of both provides a more complete assessment of patterns of inequalities and changes over time $[25,26]$.

To derive the SII and RII, each woman in the study population was assigned a notional socio-economic rank score, scaled to take values between 0 (bottom of hierarchy (Q1)) and 1 (top of hierarchy (Q4)) [8]. The rank score equals the midpoint of the range in the cumulative distribution of the population of participants in a given SEQ [24]. For example, if the Q1 women comprise $34.5 \%$ of the population, the women in this category are assigned a rank score of 0.17 (0.345/2), and if the Q2 women comprises $32.5 \%$ of the population, the corresponding rank score is $0.51(0.345$
$+[0.325 / 2])$ and so forth. The generated individual data is self-weighted and the only weight applied in the analysis is the survey weight to correct for survey sample design.

We then used generalised linear models (GLM) to fit binomial models (Eq. 1) to generate inequality measures, as has been suggested by several authors [24, 27-30].

$$
g(Y)=\beta_{0}+\beta_{1} \text { rscore }+\beta_{2} \text { survey }+\varepsilon
$$

where $\mathrm{Y}=1$ if outcome is present and $\mathrm{Y}=0$ if absent, $g(Y)=Y$ is the identity link function (i.e. binomial regression) generating SII together with the $95 \%$ confidence and, $g(Y)=\log (Y)$ is $\log$ link function (i.e. log-binomial regression) generating the RII and the $95 \%$ confidence interval, rscore is the notional socio-economic rank score for each woman, $\beta_{1}$ and $\beta_{2}$ are the regression coefficients. Survey equals 1 for the 2008 survey and 2 for the 2012 survey, and $\varepsilon$ is the error term with a binomial distribution.

The SII, the $\beta_{1}$ under binomial regression, represent the estimated difference in predicted value of the outcome between those at the top (wealthiest) and those at the bottom (poorest) of the social hierarchy. SII is the absolute effect on health outcome of moving from the poorest to the wealthiest group [20,31]. A positive SII represent inequality in favour of the wealthy, while a negative SII is inequality in favour of poor.

The RII, the exponential of the slope, $\exp \left(\beta_{1}\right)$ under log-binomial regression, represents the proportionate difference in outcome across the distribution of socioeconomic position; or the likelihood of having an outcome, relative to one's SES level. The RII increases from zero, with higher values indicating higher inequality. An RII above one indicates that the outcome is more prevalent among wealthy women, compared to their poor counterparts. To deal with lack of model convergence, we fitted Poisson regression with robust variance [32]. Poisson regression is suitable when outcomes are not rare, as in this study where most had prevalence greater than $10 \%[28]$. A decline in both SII and RII is the best evidence of progress in closing the inequality gap [24].

For each outcome, the linear trends of the RII and SII over the five year period 2008-2012 were tested by estimating the p-value for an interaction term between rank score and years since baseline, i.e. 2008 survey coded 1, 2012 coded 2, to account for the different time intervals between surveys (Eq. 2). Positive and significant coefficients, $\beta_{3}$ greater than one, for the interaction term indicate widening RII (SII) inequalities over time.

$$
\begin{aligned}
g(Y)= & \beta_{0}+\beta_{1} \text { rscore }+\beta_{2} \text { survey }+\beta_{3} \text { rscore } \\
& * \text { survey }+\varepsilon
\end{aligned}
$$




\section{Concentration index}

The concentration index is defined with reference to the concentration curve, which plots the cumulative proportion of health outcome against the cumulative proportion of the population, ranked by SEQ beginning with the poorest $[8,33]$. If health access is equally distributed across SEQ, concentration curves coincide with the diagonal line of equality. The Concentration Index is given by twice the area between the concentration curve and line of equality and ranges from -1 to 1 . Zero represents perfect equality, while positive values indicate richer individuals have greater coverage (or good health outcomes) than poorer individuals [33].

\section{Results}

In 2008 , data were gathered on 23,308 people, and $56.0 \%$ of those interviewed were women aged 15-55 years $(8292 / 14,798)$. Of these women, $13.5 \%(1121 / 8292)$ had been pregnant in the preceding 2 years, and $15.8 \%$ $(1310 / 8292)$ had a child in the past 2 years. The proportion of survey participants aged 15-55 years in 2012 was similar to that in 2008 (53.5\%; 13,187/24,659). Of these, $12.5 \%(1648 / 13,187)$ had been pregnant or had a child in the past 2 years.

\section{Variation in socio-economic characteristics of women by population group}

In both surveys, about $95 \%$ of pregnancies occurred in African or Coloured women (Table 1). White and Indian women, however, constituted $33.6 \%$ of the wealthiest quartile in 2012, higher than levels in 2008 (23.9\%). In each survey, about $60 \%$ of women in QI and QII were single, while this figure was only $40 \%$ among the wealthiest women. Wealth quartile remains strongly associated with educational attainment and employment. Overall, educational attainment appears to be rising (44.2\% of women had completed secondary school in 2012 , versus $40.0 \%$ in 2008). However, still only about $10 \%$ of the population had any post-school education in 2012. The proportion unemployed and seeking work was higher in 2012 than in 2008 in QI (51.6 versus $44.0 \%$ ) and QII (49.2 versus $33.9 \%$ ), while it decreased in the two wealthier quartiles.

Socio-economic status varies considerably between provinces, and across urban and rural divides. In each survey, pregnant women in the wealthiest two quartiles were heavily concentrated in the urban formal areas of Gauteng and Western Cape. By contrast, almost three quarters of the poorest quartile lived in rural informal locations in 2012, up from $61.0 \%$ in 2008. In the 2012 survey, the poorest quartile mostly lives in KwaZulu Natal (20.9 \%), Eastern Cape (30.9 \%) and Limpopo (19.5 \%). Few wealthy women inhabit the latter two provinces (they together constituted only about $5 \%$ of the wealthiest quartile in 2012).

\section{Inequalities in access to maternal health services}

About $10 \%$ of the overall population had not accessed ANC in 2012. Compared with 2008, receipt of any ANC declined in 2012 among all women and across almost all sub-groups, but especially in QI and QII women (Additional file 1: Table S1 and Fig. 1). Among those who attended ANC, the overall proportion that had four or more ANC visits was similar in 2008 and 2012, but inequalities within many population groups worsened. The gap between the poorest and wealthiest quartile rose from $5.7 \%$ in 2008 to $16.0 \%$ in 2012. In 2012, the proportion attending four or more visits rose with age and with each increase in education level (for example, from $72.9 \%$ in those with under three years of schooling to $94.7 \%$ in those with tertiary education), and was much higher in employed than unemployed women.

In 2012, considerably more women attended $A N C$ before 20 weeks than in 2008, with double digit increases seen in most population groups, even in the poorest quartile. Though no changes were detected in inequalities over time, the SII (0.31) and RII (1.59) remained very high in 2012. Differences in 2012 were above $20 \%$ between the sub-categories of almost all of the PROGRESS-Plus groups. Moreover, significant differences between more and less vulnerable groups were detected in early attendance for nine population subgroups in 2012, but for only three in 2008 (Additional file 1: Table S1). In the 2012 survey, ANC attendance before 20 weeks was particularly low among women under 20 years, those living in rural and urban informal areas, and in Black African women. Importantly, $75.2 \%$ of HIV-infected women attended before 20 weeks, compared to $63.5 \%$ of uninfected women.

The substantial levels of absolute and relative inequality in $S B A$ coverage were maintained in the second survey. Relatively low SBA coverage persists in QI, Black African women, rural areas and low education groups. Based on all measures of socio-economic inequality, doctor attending childbirth remains the most unequal of measures ( $\mathrm{CI}=0.27$ in 2012, for example). Overall, the proportion of deliveries attended by a doctor had, however, increased considerably in 2012 in almost population groups, but was accompanied by a worsening of absolute inequalities (QI-QIV range and SII). The SII measure shows a 58.7 percentage point increase between the lowest and highest income quartiles. Gaps between race groups also rose $(90 \%$ of White and Indian women had a doctor present in 2012, 20-30\% higher than in 2008, while in Black African women, these levels only increased from $23.5 \%$ in 2008 to $28.4 \%$ in 2012).

Marked increments were noted in HIV testing in 2012, with these services largely pro-poor. More than $90 \%$ of all population sub-groups had an HIV test in the past 
Table 1 Distribution of socio-economic status among women pregnant in past 2 years between 2008 and 2012; Distribution of socioeconomic status among population sub-groups in women pregnant in past 2 years: analysis of the 2008 and 2012 national SABSSM survey

\begin{tabular}{|c|c|c|c|c|c|c|c|c|c|c|}
\hline & \multicolumn{8}{|c|}{ Socio-economic Status } & \multirow{2}{*}{\multicolumn{2}{|c|}{$\begin{array}{l}\text { Overall total } \\
\text { (Unweighted } N, \%)\end{array}$}} \\
\hline & \multicolumn{2}{|c|}{ QI poorest (\%) } & \multicolumn{2}{|l|}{ QII (\%) } & \multicolumn{2}{|c|}{ QIII (\%) } & \multicolumn{2}{|c|}{ QIV wealthiest (\%) } & & \\
\hline & 2008 & 2012 & 2008 & 2012 & 2008 & 2012 & 2008 & 2012 & 2008 & 2012 \\
\hline Age categories & & & & & & & & & 1111 & $1619^{* *}$ \\
\hline 15 to 19 & 12.1 & 14.2 & 13.1 & 9.5 & 9.6 & 9.9 & 4.6 & 4.6 & 11.1 & 10.2 \\
\hline 20 to 29 & 50.4 & 50.8 & 48.6 & 57.8 & 52.4 & 55.3 & 51.4 & 50.6 & 50.5 & 54.0 \\
\hline 30 to 39 & 32.8 & 26.2 & 36.2 & 28.9 & 35.5 & 31.4 & 37.0 & 39.8 & 35.0 & 30.4 \\
\hline 40 to 55 & 4.7 & 8.8 & 2.1 & 3.8 & 2.4 & 3.5 & 6.9 & 4.9 & 3.4 & 5.3 \\
\hline Place of residence & & & & & & & & & $1115^{* * *}$ & $1619^{* * *}$ \\
\hline Urban formal & 7.8 & 11.3 & 27.6 & 27.1 & 82.0 & 76.8 & 95.7 & 89.7 & 43.2 & 45.7 \\
\hline Urban informal & 20.3 & 11.0 & 16.3 & 12.0 & 7.6 & 9.1 & 1.5 & 1.0 & 13.7 & 9.3 \\
\hline Rural formal & 10.9 & 4.8 & 9.7 & 3.1 & 6.3 & 2.9 & 0.3 & 6 & 8.3 & 3.9 \\
\hline Rural informal & 61.0 & 72.8 & 46.4 & 57.8 & 4.2 & 11.3 & 2.5 & 3.3 & 34.8 & 41.1 \\
\hline Province & & & & & & & & & $1115^{* * *}$ & $1619^{* * *}$ \\
\hline Eastern Cape & 21.2 & 30.9 & 8.2 & 7.1 & 8.5 & 4.6 & 15.0 & 2.3 & 12.8 & 12.6 \\
\hline Free State & 3.5 & 3.2 & 6.6 & 5.8 & 4.7 & 6.4 & 3.2 & 6.9 & 4.8 & 5.4 \\
\hline Gauteng & 10.5 & 8.5 & 8.2 & 18.3 & 41.2 & 40.6 & 40.4 & 50.5 & 21.3 & 26.4 \\
\hline KwaZulu Natal & 23.2 & 20.9 & 28.7 & 26.2 & 16 & 12.3 & 9.9 & 10.0 & 21.7 & 18.4 \\
\hline Limpopo & 22.4 & 19.5 & 15.0 & 15.4 & 2.8 & 3.7 & 2.9 & 2.5 & 12.7 & 11.4 \\
\hline Mpumalanga & 8.0 & 6.5 & 10.4 & 12.9 & 3.4 & 7.0 & 8.5 & 3.7 & 7.5 & 8.1 \\
\hline North West & 7.8 & 6.8 & 13.7 & 8.1 & 8.2 & 6.0 & 1.3 & 4.7 & 9.2 & 6.6 \\
\hline Northern Cape & 1.2 & 1.2 & 1.7 & 1.2 & 2.3 & 5.1 & 2.1 & 3.9 & 1.8 & 2.7 \\
\hline Western Cape & 2.1 & 2.6 & 7.4 & 4.9 & 12.9 & 14.3 & 16.7 & 15.5 & 8.2 & 8.4 \\
\hline Race & & & & & & & & & $1110^{* * *}$ & $1615^{* * *}$ \\
\hline African & 98.4 & 96.9 & 95 & 95.7 & 77.5 & 82.9 & 60.4 & 49.7 & 88 & 85.7 \\
\hline White & 0.0 & 0.1 & 0.3 & 0.0 & 8.1 & 2.0 & 17.6 & 23.4 & 4.0 & 4.0 \\
\hline Coloured & 1.6 & 3.0 & 4.5 & 4.2 & 13.0 & 13.2 & 15.7 & 16.7 & 7.1 & 8.2 \\
\hline Indian & 0.0 & 0.0 & 0.1 & 0.1 & 1.4 & 1.8 & 6.3 & 10.2 & 1.0 & 2.0 \\
\hline Highest education & & & & & & & & & $1111^{* * *}$ & $1471^{* * *}$ \\
\hline No schooling-Gr3 & 7.1 & 3.6 & 5.3 & 2.5 & 1.7 & 1.2 & 0.2 & 1.2 & 4.4 & 2.3 \\
\hline Gr4-Gr7 & 17.8 & 19.0 & 10.1 & 7.9 & 5.4 & 4.2 & 2.8 & 1.8 & 10.4 & 9.2 \\
\hline Gr8-Gr11 & 58.3 & 60.9 & 51.4 & 44.0 & 34.4 & 40.0 & 13.8 & 20.5 & 45.3 & 44.4 \\
\hline Gr12 & 15.2 & 16.4 & 28.6 & 39.9 & 44.0 & 41.6 & 36.2 & 44.1 & 29.7 & 34.2 \\
\hline Tertiary & 1.7 & 0.1 & 4.6 & 5.7 & 14.6 & 13.0 & 47.0 & 32.4 & 10.3 & 10.0 \\
\hline Employment & & & & & & & & & $1096^{* * *}$ & $1589^{* * *}$ \\
\hline Housewife & 26.2 & 17.0 & 21.1 & 11.2 & 13.8 & 12.5 & 11 & 17.5 & 19.6 & 14.2 \\
\hline Unemployed, not seeking work & 9.6 & 10.9 & 10.0 & 7.6 & 3.4 & 7.0 & 2.0 & 2.3 & 7.3 & 7.6 \\
\hline Unemployed, seeking work & 44.0 & 51.6 & 33.9 & 49.2 & 36.2 & 35.6 & 28.1 & 12.7 & 37.2 & 40.7 \\
\hline Informal sector, self-employed & 4.6 & 0.6 & 6.0 & 3.4 & 6.3 & 7.2 & 9.6 & 7.0 & 6.0 & 4.2 \\
\hline Scholar or student & 5.6 & 11.9 & 13.3 & 10.1 & 5.6 & 10.1 & 2.4 & 4.9 & 7.7 & 9.8 \\
\hline Part employed & 6.5 & 3.6 & 4.1 & 5.5 & 4.0 & 7.7 & 4.0 & 14.2 & 4.8 & 6.8 \\
\hline Full employed & 2.4 & 2.5 & 10.7 & 11.1 & 28.9 & 18.3 & 43.0 & 38.4 & 16.2 & 14.7 \\
\hline Pensioner, sick or disabled & 1.2 & 1.9 & 1.0 & 1.9 & 1.8 & 1.7 & 0.1 & 3.0 & 1.2 & 2.0 \\
\hline
\end{tabular}


Table 1 Distribution of socio-economic status among women pregnant in past 2 years between 2008 and 2012; Distribution of socioeconomic status among population sub-groups in women pregnant in past 2 years: analysis of the 2008 and 2012 national SABSSM survey (Continued)

\begin{tabular}{|c|c|c|c|c|c|c|c|c|c|c|}
\hline Marital status & & & & & & & & & $1113^{* *}$ & $1601^{* * *}$ \\
\hline Single & 59.3 & 57.8 & 64.8 & 62 & 55.7 & 50.2 & 41.1 & 36.1 & 58.4 & 53.7 \\
\hline Married/cohabiting & 36.5 & 38.7 & 32.7 & 35.6 & 43.2 & 48.2 & 55.0 & 63.5 & 38.9 & 44.1 \\
\hline Divorced/widow & 4.1 & 3.5 & 2.5 & 2.4 & 1.2 & 1.6 & 3.9 & 0.5 & 2.7 & 2.2 \\
\hline
\end{tabular}

Distribution of socio-economic status among population sub-groups in women pregnant in past 2 years: analysis of the 2008 and 2012 national SABSSM survey. Table shows column percentages. $P$ value assesses the distribution of population group across quartiles; ${ }^{* *} P<0.01 ; * * * P<0.001$

two years, considerably higher than in 2008. Of concern, however, testing levels were relatively low among some groups that had the highest HIV prevalence. For example, the following groups had an HIV prevalence above $20 \%$ and more than $5 \%$ had never tested: women $40-55$ years, housewives, married or cohabiting women, unemployed women not seeking work, those who did not complete primary school, and women living in rural formal areas, or Gauteng and Mpumalanga Provinces. Still in 2012, some $3.9 \%$ of HIV-infected women said they had never tested.

\section{Distribution of planned pregnancy and fertility}

The overall proportion of pregnancies that were planned declined from $44.6 \%$ in 2008 to $34.7 \%$ in 2012, with the largest drop amongst the poorest quartile (Additional file 2: Table S2 and Fig. 1). Further, in 2012, more considerable step-wise decreases were noted in the proportion of planned pregnancy with each SEQ, and the rises in SII and RII indicate growing inequalities in this outcome $(\mathrm{RII}=1.4$ in 2008 and 3.0 in 2012; and SII $=0.13$ in 2008 and 0.39 in 2012; Table 2).

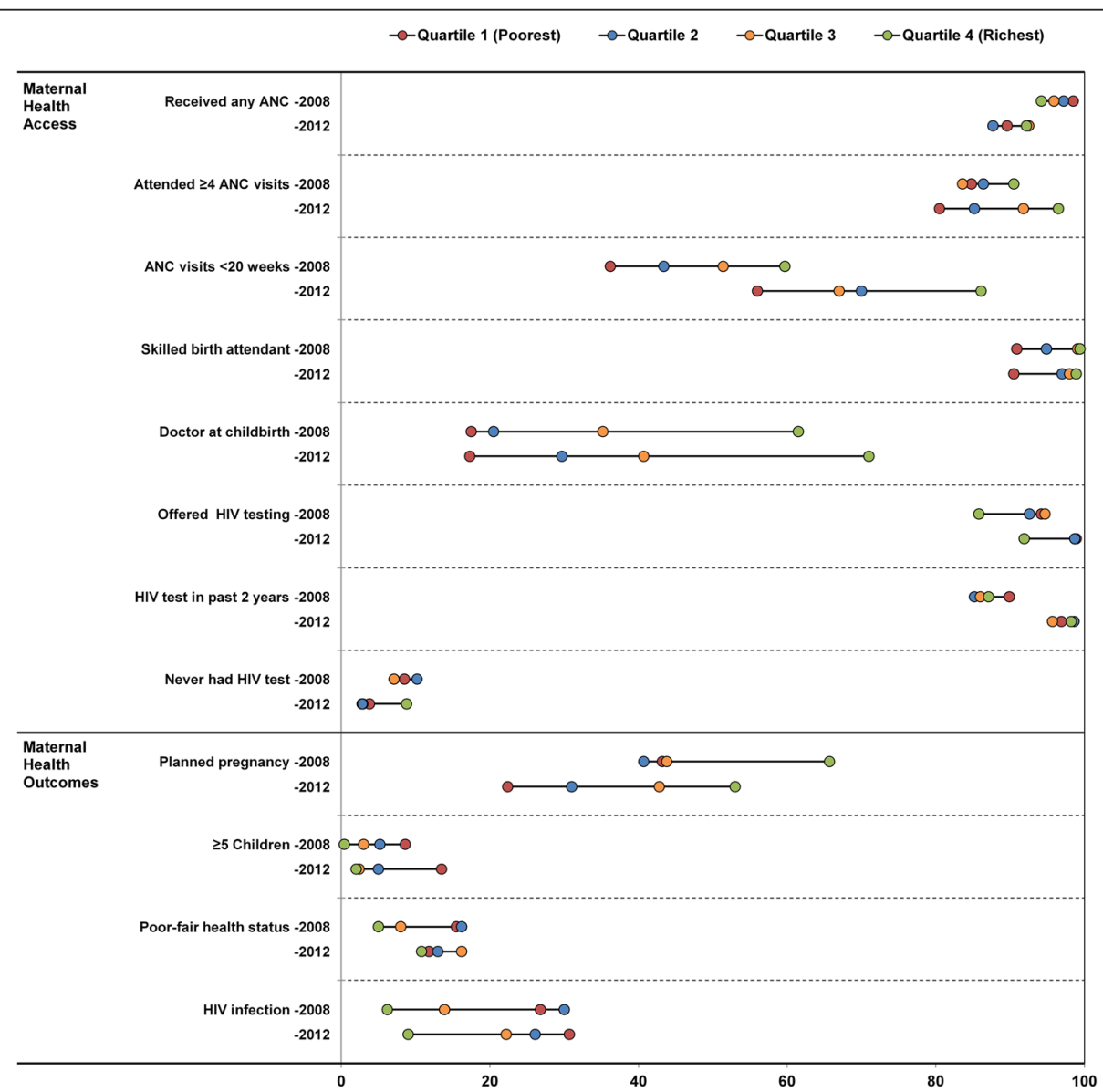

Fig. 1 Time differentials in coverage of maternal health services and health status in South Africa; Time differentials in coverage of maternal health services and in maternal health status across socio- economic quartiles in South Africa 
Table 2 Trends in SII and RII in access to maternal health services and in health status; Trends in absolute and relative socio-economic inequalities in access to maternal health services and in maternal health status in South Africa

\begin{tabular}{|c|c|c|c|c|c|c|c|c|c|c|}
\hline \multirow[t]{2}{*}{ Variable } & \multicolumn{2}{|c|}{ Range (Q4-Q1) } & \multicolumn{3}{|c|}{$\begin{array}{l}\text { Slope of index } \\
\text { inequality }(95 \% \mathrm{Cl})\end{array}$} & \multicolumn{3}{|c|}{$\begin{array}{l}\text { Relative index of } \\
\text { inequality }(95 \% \mathrm{Cl})\end{array}$} & \multicolumn{2}{|c|}{$\begin{array}{l}\text { Concentration } \\
\text { Index }\end{array}$} \\
\hline & 2008 & 2012 & 2008 & 2012 & Change in equity ( $P$-value) & 2008 & 2012 & Change in equity ( $P$-value) & 2008 & 2012 \\
\hline Received any ANC & -4.3 & 2.6 & $\begin{array}{l}-0.047^{* *} \\
(-0.094--0.001)\end{array}$ & $\begin{array}{l}0.051 \\
(-0.027-0.130)\end{array}$ & 0.030 & $\begin{array}{l}0.951^{* *} \\
(0.904-1.000)\end{array}$ & $\begin{array}{l}1.056 \\
(0.971-1.149)\end{array}$ & 0.037 & -0.005 & 0.015 \\
\hline Attended $\geq 4$ ANC visits & 5.7 & 16.0 & $\begin{array}{l}0.024 \\
(-0.084-0.132)\end{array}$ & $\begin{array}{l}0.209^{* * *} \\
(0.129-0.288)\end{array}$ & 0.005 & $\begin{array}{l}1.027 \\
(0.909-1.160)\end{array}$ & $\begin{array}{l}1.271^{* * *} \\
(1.139-1.417)\end{array}$ & 0.008 & 0.011 & 0.033 \\
\hline ANC visit $<20$ weeks gestation & 23.5 & 30.1 & $\begin{array}{l}0.274^{* * *} \\
(0.106-0.442)\end{array}$ & $\begin{array}{l}0.312^{* * *} \\
(0.165-0.460)\end{array}$ & 0.741 & $\begin{array}{l}1.831^{* * *} \\
(1.268-2.644)\end{array}$ & $\begin{array}{l}1.593^{* * *} \\
(1.278-1.984)\end{array}$ & 0.525 & 0.116 & 0.077 \\
\hline Skilled birth attendant & 8.5 & 8.4 & $\begin{array}{l}0.121^{* * *} \\
(0.066-0.176)\end{array}$ & $\begin{array}{l}0.113^{* *} \\
(0.020-0.207)\end{array}$ & 0.888 & $\begin{array}{l}1.135^{* * *} \\
(1.071-1.202)\end{array}$ & $\begin{array}{l}1.124^{* *} \\
(1.021-1.238)\end{array}$ & 0.869 & 0.017 & 0.018 \\
\hline Doctor attended childbirth & 44 & 53.7 & $\begin{array}{l}0.401^{* * *} \\
(0.270-0.531)\end{array}$ & $\begin{array}{l}0.587^{* * *} \\
(0.449-0.724)\end{array}$ & 0.063 & $\begin{array}{l}5.285^{* * *} \\
(2.971-9.398)\end{array}$ & $\begin{array}{l}5.802^{* * *} \\
(3.856-8.728)\end{array}$ & 0.797 & 0.300 & 0.268 \\
\hline Offered HIV testing in pregnancy & -8.4 & -7.0 & $\begin{array}{l}-0.042 \\
(-0.106-0.021)\end{array}$ & $\begin{array}{l}-0.042 \\
(-0.093-0.009)\end{array}$ & 0.999 & $\begin{array}{l}0.951 \\
(0.880-1.028)\end{array}$ & $\begin{array}{l}0.940 \\
(0.862-1.024)\end{array}$ & 0.833 & -0.007 & -0.004 \\
\hline HIV test in past 2 years & -2.8 & 1.3 & $\begin{array}{l}-0.050 \\
(-0.152-0.051)\end{array}$ & $\begin{array}{l}-0.004 \\
(-0.049-0.041)\end{array}$ & 0.419 & $\begin{array}{l}0.943 \\
(0.838-1.061)\end{array}$ & $\begin{array}{l}0.996 \\
(0.951-1.042)\end{array}$ & 0.405 & 0.000 & -0.006 \\
\hline Never had HIV Test & -1.4 & 5.0 & $\begin{array}{l}-0.028 \\
(-0.120-0.065)\end{array}$ & $\begin{array}{l}0.030 \\
(-0.031-0.091)\end{array}$ & 0.297 & $\begin{array}{l}0.739 \\
(0.264-2.068)\end{array}$ & $\begin{array}{l}2.631 \\
(0.395-17.518)\end{array}$ & 0.236 & -0.001 & 0.450 \\
\hline Planned pregnancy & 22.5 & 30.6 & $\begin{array}{l}0.134 \\
(-0.032-0.301)\end{array}$ & $\begin{array}{l}0.391^{* * *} \\
(0.258-0.524)\end{array}$ & 0.009 & $\begin{array}{l}1.391 \\
(0.929-2.084)\end{array}$ & $\begin{array}{l}2.999^{* * *} \\
(2.096-4.292)\end{array}$ & 0.004 & 0.078 & 0.161 \\
\hline Five or more children & -8.2 & -11.5 & $\begin{array}{l}-0.099^{* * *} \\
(-0.139--0.060)\end{array}$ & $\begin{array}{l}-0.117^{* * *} \\
(-0.162--0.073)\end{array}$ & 0.548 & $\begin{array}{l}0.129^{* * *} \\
(0.033-0.497)\end{array}$ & $\begin{array}{l}0.045^{* * *} \\
(0.014-0.144)\end{array}$ & 0.255 & -0.326 & -0.324 \\
\hline Poor-fair health status & -10.5 & -1.0 & $\begin{array}{l}-0.150^{* * *} \\
(-0.234--0.066)\end{array}$ & $\begin{array}{l}0.022 \\
(-0.068-0.112)\end{array}$ & 0.004 & $\begin{array}{l}0.331^{* * *} \\
(0.167-0.654)\end{array}$ & $\begin{array}{l}1.165 \\
(0.631-2.151)\end{array}$ & 0.004 & -0.043 & -0.040 \\
\hline HIV infection & -20.6 & -21.7 & $\begin{array}{l}-0.281^{* * *} \\
(-0.427--0.136)\end{array}$ & $\begin{array}{l}-0.251^{* * *} \\
(-0.372--0.129)\end{array}$ & 0.38 & $\begin{array}{l}0.340^{* * *} \\
(0.178-0.649)\end{array}$ & $\begin{array}{l}0.372^{* * *} \\
(0.224-0.620)\end{array}$ & 0.821 & -0.193 & -0.213 \\
\hline
\end{tabular}

Trends in absolute and relative socio-economic inequalities in access to maternal health services and in maternal health status in South Africa: the repeated cross-sectional national SABSSM surveys 2008 and 2012 ${ }^{* *} P<0.01$; ${ }^{* *} P<0.001$ 
In both surveys, only about a third of HIV-infected women reported having had a planned pregnancy. In 2012, levels of unplanned pregnancy were highest in informal areas (both rural and urban ones), which have the highest HIV prevalence of all places of residence. Among women younger than 20 years in the second survey, only $8.7 \%$ of pregnancies were planned. Scholars and students accounted for $9.8 \%$ of all pregnancies in 2012, while only $7.7 \%$ in 2008.

The markedly unequal distribution of multiparous women across socio-economic groups persists: in 2012, $13.5 \%$ of QI women had a parity of five or more, while this figure was $6.4 \%$ in QIV women (Fig. 1). Also, only $3.5 \%$ of women in formal urban areas had five or more children, compared with about $9.0 \%$ in rural areas.

\section{Inequalities in maternal health status and in prevalence of HIV infection}

Overall, in both surveys, around $13 \%$ of women described themselves as being in poor or fair health. However, unlike in 2008, the proportion of women reporting this outcome in 2012 was very similar between SEQs, thus reflecting a narrowing of relative and absolute inequalities over time (Table 2). The proportion of HIVinfected women with a poor-fair health status was lower in $2012(20.2 \%)$ than in 2008 (25.1\%; Additional file 2: Table S2). In 2012, however, the proportions with poor or fair health increase stepwise with age category or decrease in education group.

The distribution of HIV infection among population groups in 2012 remained markedly unequal, though inequalities between SEQs were stable. HIV status is strongly associated with demographic and socio-economic characteristics - in both surveys, there are double digit absolute percentage differentials within each of the PROGRESS-Plus groups.

\section{Inequalities in access and outcomes between different provinces}

Large differences were noted at provincial level for almost all the indicators studied, and access to services even declined in some provinces (Fig. 2). For example, compared with 2008, coverage of SBA decreased in 2012 in the Eastern Cape and North West Provinces. Gauteng had widened socioeconomic inequalities in the indicator ANC attendance before 20 weeks, while the relative inequalities in this variable narrowed in Western Cape, Eastern Cape and KwaZulu Natal (Fig. 2). Disparities also widened in 2012 compared to 2008 for self-reported health status in the North West and Gauteng provinces, but were narrower in the Western Cape. Inequalities for planned pregnancy were also wider in the Free State and North West provinces in 2012 compared to 2008. Lastly, in the two provinces with the highest HIV prevalence, KwaZulu
Natal and Mpumalanga, only $21.8 \%$ and $25.2 \%$ of pregnancies were planned respectively.

Overall, the Eastern Cape Province still has the poorest access to services for many measures, aside from HIV testing, which had approximated national levels by 2012. Compared with the national average, in the Eastern Cape, 9.0 \% fewer women had four or more ANC visits; $18.0 \%$ less attended ANC before 20 weeks of pregnancy; and SBA coverage was $8.2 \%$ lower. Moreover, in contrast with other provinces, coverage of some services in the Eastern Cape actually declined between 2008 and 2012. Planned pregnancy in the province decreased from $38.1 \%$ in 2008 to $18.8 \%$ in 2012 and HIV prevalence rose from 18.6 to $25.1 \%$.

\section{Discussion}

The extraordinarily high levels of inequalities noted in 2008 persist and were even exacerbated in many of the services studied. Several underlying disparities in the social determinants of health also worsened. Moreover, substantial declines took place in the overall coverage of ANC services and in planned pregnancy in the country. Encouragingly, however, some notable advances have occurred in access to maternal health services in the country as a whole. HIV testing coverage rose nationally, as did early ANC attendance and the likelihood of having a doctor present at birth. Also, inequalities detected in health status and in HIV testing in 2008 were no longer present by 2012. Improvements in health status may be due to the high coverage of ART, and consequent gains in health among HIV-infected women, who are predominately in QI and QII.

Inequalities experienced by several PROGRESS-Plus groups warrant specific mention. Overall, compared with other race groups, Black African women had poorer access to services and health outcomes on several indicators, most notably early ANC attendance, skilled birth attendance, planned pregnancy and HIV prevalence. These findings are particularly concerning given the strong links between these indicators and the risk for mother-to-child transmission of HIV (MTCT). As in 2008, education level was linked with almost all measures of access to services and health outcomes. Though the proportion of women completing secondary school in lower economic groups appears to be rising, these are matched by worsening inequities in employment. Also noteworthy, rural areas experienced several deficiencies in service delivery, particularly in access to a SBA. Poorer socio-economic groups are increasingly concentrated within the Eastern Cape, and several services there actually deteriorated over the study period. Service delivery deficiencies were also noted in North West Province, albeit to a lessor extent than the Eastern Cape. Both these provinces are plagued with corruption [34, 35]. 

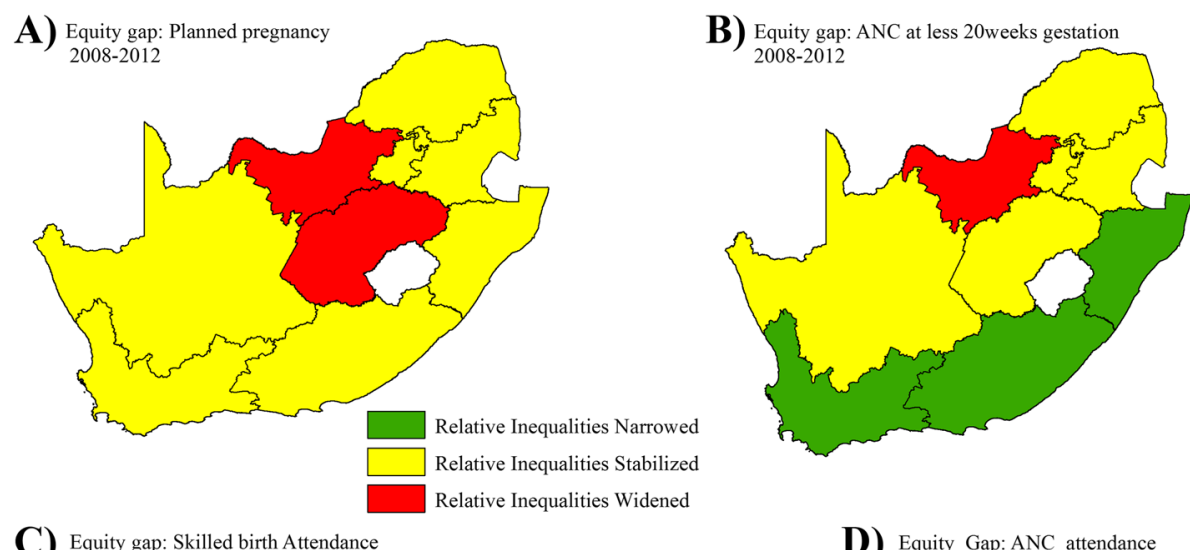
C) Equity gap: Skilled birth Attendance
2008-2012
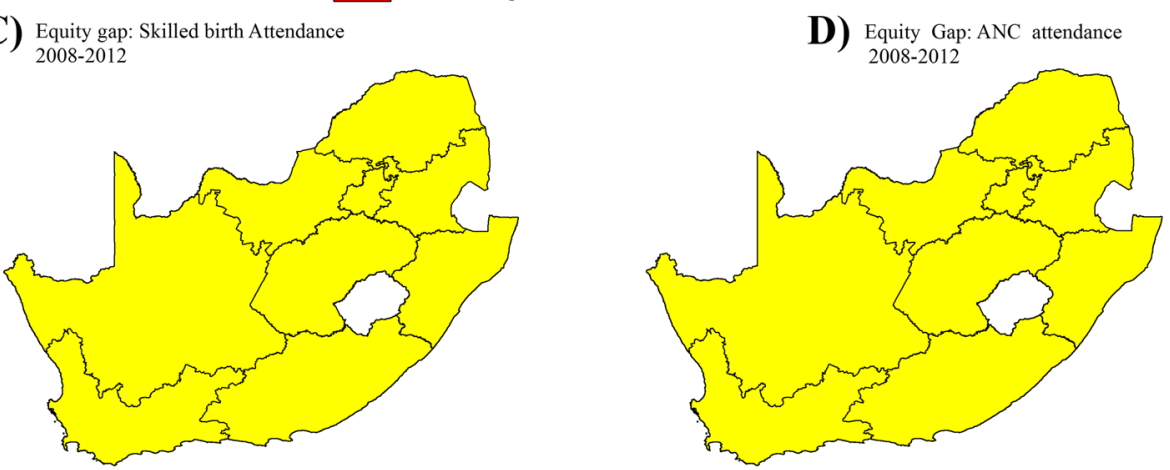

E) Equity gap: Self reported health status
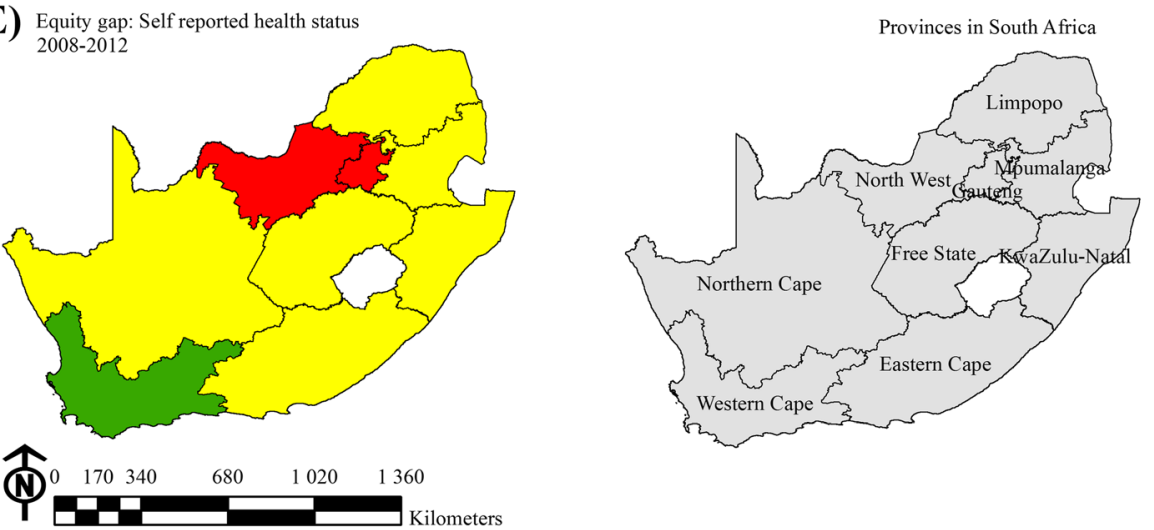

Fig. 2 RII differentials in Planned pregnancy, SBA, ANC, health status, ANC at less 20 weeks gestation; Provincial differentials in RII in Planned pregnancy, SBA, ANC, health status and ANC at less than 20 weeks gestation over 5 years period in South Africa. Yellow represent provinces with stable high RII, Green indicates provinces where RII narrowed, an improvement, and red indicate provinces where RII widened indicating a high equity gap in access between wealthy and poor women

Differentials in coverage of services must also be interpreted in the light of markedly asymmetric needs between population groups, as measured by HIV status, for example. HIV prevalence in the poorest quartile is 20 percentage points higher than in the wealthiest women, signalling the chronic deficiencies in access to highquality health, education and social services in the country. HIV remains the preeminent risk factor for maternal morbidity and mortality in the country $[36,37]$ and infected women require more, not equal, levels of services. It is, however, precisely those with the highest levels of need that remain underserved. Still 5 percent of women have never accessed HIV testing, which should be universally provided for all pregnant women in the country [38]. Non-testing is even higher in some groups with a high HIV prevalence, many of whom might mistakenly perceive themselves to be at low risk, as they are older, married housewives, or feel protected by living within a rural traditional society. Information campaigns could focus on addressing these misperceptions. Gaps in HIV testing among older women also perhaps reflect the difficulties of an often considerably younger peer counsellor in discussing HIV testing and sexual matters with older women. 
Timely and frequent attendance at ANC and for facility birth are especially important for preventing MTCT and conditions such as hypertension, anaemia, and fetal alcohol spectrum disorders, which require early detection and repeated interventions during pregnancy. As ART is now widely available [39], the most critical factor which determines whether a woman transmits HIV to her infant is the duration of ART during pregnancy [40, 41]. Demand- and supply-side interventions could reverse the concerning disparities noted and overall gaps in these services.

The persistent, even escalating, socially-determined inequities in service access support the call for state support during pregnancy in South Africa [42]. Moreover, the widening of unemployment differentials indicates that income-related inequities among pregnant women are actually worsening. The existing child support grant in South Africa, widely credited with improving child health in the country [43], should be initiated during pregnancy to alleviate the indirect costs of accessing services, such as transport and childcare while away from the family [42]. Grants given during pregnancy have raised service utilisation in many Latin American and South East Asian countries, and have led to marked improvements in maternal and child health outcomes [44].

Attention paid to family planning has risen in recent years, both globally and within South Africa [45]. Increases in unintended pregnancy, especially among young women and scholars, as well as a widening of inequalities in this outcome, indicate that a focus on family planning is long overdue. Improvements in family planning services would lower maternal, neonatal and infant mortality, and assist in reaching the MTCT elimination targets (nearly $70 \%$ of pregnancies among HIV-infected women were unplanned in both surveys) [46]. It will be important to monitor whether family planning services have improved following the Contraceptive Policy introduced in South Africa in 2013.

\section{Limitations}

Aside from biological measures of HIV status, many outcomes were self-reported, and subject to social desirability and recall biases. Self-assessed health status may be especially vulnerable to misclassification. Although this measure is associated with morbidity and predicts mortality, its validity may vary across population groups [47-49]. As a further limitation, we did not adjust the socio-economic inequality measures for potential confounding variables, such as race, education and geographical areas. Indeed, the analysis largely focused on impacts of socio-economic inequalities, and only presents salient findings related to the other PROGRESS-Plus groups.
The proportion ineligible or declining participation in the surveys was substantial. Plausibly, those declining enrolment may, for example, have had different health-seeking behaviours than those who participated. Moreover, wealthier and white race groups were more likely to decline survey participation [10], groups that might incur specific forms of measurement bias. For example, wealthy women who visited a private-sector obstetrician during pregnancy may have reported not having received antenatal care during pregnancy. Finally, in future studies, measuring distance to a facility could provide a better assessment of geographical access than simple rural and urban dichotomies. This information and data from tools such as Global Positioning Systems could be used for pinpointing poorly performing areas.

\section{Conclusions}

The most striking finding is the widening of both absolute and relative inequalities in several measures of access to care. Even in measures where inequalities did not rise, substantial disparities persist. Encouragingly, differences in overall health status between quartiles narrowed.

This analysis provides actionable information by identifying which interventions and groups require most attention. Considerable gains could be made by targeting underserved groups, as well as the factors underlying the differences in access, such as poor quality services and unsatisfactory patient experiences. Clearly, the continued deficiencies, even deterioration in service delivery in the Eastern Cape and North West Provinces warrant attention. Furthermore, to reach the country's targets for elimination of HIV infection in children, government should focus on improving access to HIV testing in groups which have relatively low HIV testing coverage, but high HIV prevalence, such as older women. Strengthening of family planning services, especially for teenagers, scholars and other low uptake groups would also reduce HIV infections in children, among other sizable benefits.

Though the health system bears responsibility for narrowing gaps in access, factors outside the health sector, such as unemployment, also account for demand for care and population health more broadly $[2$, 50]. Demand side interventions could incentivise early and frequent ANC visits. This might be achieved by beginning the child support grant in pregnancy and requiring an ANC card as part of grant enrolment procedures. Finally, policy makers will need to choose between prioritising further overall improvements in health services (noted on several indicators in this study), or redressing the uneven improvements that have taken place. 


\section{Additional files}

Additional file 1: Table S1. Results on inequalities in access to maternal health services across different populations groups in South Africa. (DOCX $35 \mathrm{~kb}$ )

Additional file 2: Table S2. Results on inequalities in maternal health outcomes across different populations groups in South Africa. (DOCX $26 \mathrm{~kb})$

\section{Acknowledgements}

We thank Dr Fiona Scorgie (PhD) and Dr Brian Williams (PhD), both academic writers and native English speakers, for assisting with the copy editing the manuscript.

\section{Funding}

Financial support for survey data used in the study was from the President's Emergency Plan for AIDS Relief (PEPFAR) through the United States Centers for Disease Control and Prevention (HHS/CDC) under the terms of Cooperative Agreement number 1 U2G PS 000570 and 3U2GGH000570. The funders had no role in study design, data collection and analysis, decision to publish, or preparation of the manuscript. The study contents are solely the responsibility of the authors and do not necessarily represent the official views of the Centers for Disease Control and Prevention (CDC)

\section{Availability of data and materials}

The datasets analysed in this study are available from http:// curation.hsrc.ac.za/Datasets-PFAJLA.phtml. The blood samples described in this study have been analyzed and discarded, and so are not available for further analyses.

\section{Authors' contributions}

All authors contributed to the overall study design and specific methodologies. NW MC DB conceived the study design, performed the statistical analysis, drafted the manuscript and edited the manuscript for crucial content. ND HR OS provided critical review of the manuscript. NW coordinated the finalising the manuscript. All authors read and approved the final manuscript.

\section{Competing interests}

The author(s) declare that they have no competing interests.

\section{Consent for publication}

Not applicable

\section{Ethics approval and consent to participate}

The study was approved by the Human Science's Research Council's Research Ethics Committee (HSRC REC) and the Human Subjects Review from the Centre for Disease Control (CDC) and Prevention's Global AIDS Programme. The HSRC REC is registered with the South African National Health Research Ethics Council (REC-290808-015). The HSRC REC has US Office for Human Research Protections (OHRP) Federal-wide Assurance (FWA Organisation No. 0000 6347). Written informed consent was obtained from participants. The CDC granted a waiver of written consent per 45CFR46 for cases where respondents were unable to provide written consent, but consented verbally.

\section{Author details}

${ }^{1}$ Epidemiology and Strategic Information Unit, Human Sciences Research Council, Pretoria, South Africa. ${ }^{2}$ Wits Reproductive Health and HIV Institute, Faculty of Health Sciences, University of the Witwatersrand, Johannesburg, South Africa. ${ }^{3}$ Evidence Based Solutions, Cape Town, South Africa.

${ }^{4}$ Department of Psychiatry and Mental Health, University of Cape Town, Cape Town, South Africa. ${ }^{5}$ Centre for Health Policy, School of Public Health, Faculty of Health Sciences, University of the Witwatersrand, Johannesburg, South Africa.

Received: 22 July 2015 Accepted: 20 August 2016 Published online: 01 September 2016

\section{References}

1. The World Bank. Income share. 2011.

2. Massyn N, Day C, Peer N, Padarath A, Barron P. District Health Barometer 2013/14. Durban; 2014

3. National Department of Health. The 2012 National Antenatal Sentinel HIV \& Herpes Simplex Type-2 Prevalence Survey in South Africa. 2013.

4. Moodley J, Pattinson R, Fawcus S, Schoon M, Moran N. The confidential enquiry into maternal deaths in South Africa: a case study. Bjog. 2014;121: 53-60.

5. Department of Health. Saving Mothers: Tenth interim report on Confidential Enquiries into Maternal deaths 2011-2012. Pretoria; 2013.

6. Buchmann E, Mnyani C, Frank K, Chersich M, McIntyre J. Declining maternal mortality in the face of persistently high HIV prevalence in a middle-income country. Bjog. 2015;12:220-7.

7. Black V, Brooke SCM. Effect of human immunodeficiency virus treatment on maternal mortality at a tertiary center in South Africa: a 5-year audit. Obs Gynecol. 2009:114:292-9.

8. Wabiri N, Chersich M, Zuma K, Blaauw D, Goudge J, Dwane N. Equity in maternal health in South Africa: analysis of health service access and health status in a national household survey. PLoS One [Internet]. 2013 [cited 2013 Nov 7];8:e73864. Available from: http://www.pubmedcentral.nih.gov/ articlerender.fcgi?artid=3765324\&tool=pmcentrez\&rendertype=abstract

9. Shisana O, Rehle T, Simbayi L, Zuma K, Jooste S, Zungu N, et al. South African national HIV prevalence, incidence, behaviour and communication survey, 2012. Cape Town: HSRC Press; 2014.

10. Shisana O, Rehle T, Simbayi L, Zuma K, Jooste S, Pillay-van-Wyk V, et al. South African National HIV Prevalence, Incidence, Behaviour and Communication Survey, 2008.A Turning Tide Among Teenagers? [Internet]. Cape Town, South Africa: HSRC press; 2009. Available from: www.hsrcpress.ac.za

11. Shisana O, Rehle T, Simbayi L, Zuma K, Jooste S, Pillay-van-Wyk V, et al. South African national HIV prevalence, HIV incidence, behaviour and communication survey. Cape Town: HSRC press; 2005.

12. Rehle T, Hallet T, Shisana O, van Wyk V, Zuma K, Carrara H, et al. Decline in New HIV Infections in South Africa: Estimating HIV Incidence from Three National HIV Surveys in 2002, 2005 and 2008. PLoS One [Internet]. 2010;5. Available from: e11094. doi:10.1371/journal.pone.0011094.

13. Bartholomew D, Steele F, Moustaki I, Galbraith J. The analysis and interpretation of multivariate data for social scientists. London: Chapman \& Hall/CRC; 2002.

14. Howe LD, Hargreaves JR, Huttly SR. Issues in the construction of wealth indices for the measurement of socio-economic position in low-income countries. Emerg. Themes Epidemiol. [Internet]. 2008 [cited 2012 Mar 28];5:3. Available from: http://www.pubmedcentral.nih.gov/articlerender. fcgi?artid $=2248177 \&$ tool $=$ pmcentrez\&rendertype=abstract

15. Onwujekwe O, Uzochukwu B, Eze S, Obikeze E, Okoli C, Ochonma O. Improving equity in malaria treatment: relationship of socio-economic status with health seeking as well as with perceptions of ease of using the services of different providers for the treatment of malaria in Nigeria. Malar. J. [Internet]. 2008 [cited 2012 Jul 25];7:5. Available from: http://www. pubmedcentral.nih.gov/articlerender.fcgi?artid=2249588\&tool=pmcentrez \&rendertype $=$ abstract

16. UNFPA. Preventing HIV and unintended pregnancies: strategic framework 2011-2015. 2012

17. Tugwell $P$, Petticrew $M$, Kristjansson $E$, Welch V, Ueffing E, Waters $E$, Brockhoff J, Bonnefoy J, Morgan A, Doohan E, Kelly M P. Assessing equity in systematic reviews: realising the recommendations of the Commission on Social Determinants of Health. Bmj. 2010;341:c4739. http://dx.doi.org/10. 1136/bmi.c4739.

18. StataCorp LP. STATA/SE [Internet]. College Station, Texas, United States: StataCorp LP; 2013. Available from: www.stata.com

19. Carr-hill R, Chalmers-dixon P. The Public Health Observatory Handbook of Health Inequalities Measurement. Lin J, editor. 2005.

20. Wagstaff A, Paci P, Van Doorslaer E. On the measurement of inequalities in health. Soc Sci Med. 1991:33:545-57.

21. WHO. Health inequality monitoring with a special focus on low- and middle-income countries. Luxembourg: WHO Press; 2013.

22. Bambara C. Health inequalities and welfare state regimes: theoretical insights on a public health "puzzle". J Epidemiol Community Health. 2011:65:740-5.

23. Mackenbach J, Kunst A. Measuring the magnitude of socio-economic inequalities in health: an overview of available measures illustrated with two examples from Europe. Soc Sci Med. 1997;44:757-71. 
24. Ernstsen L, Strand BH, Nilsen SM, Espnes GA, Krokstad S. Trends in absolute and relative educational inequalities in four modifiable ischaemic heart disease risk factors: repeated cross-sectional surveys from the NordTrøndelag Health Study (HUNT) 1984-2008. BMC Public Health [Internet]. BioMed Central Ltd; 2012;12:266. Available from: http://www.pubmedcentral. nih.gov/articlerender.fcgi?artid=3434116\&tool=pmcentrez\&rendertype $=$ abstract

25. Asada Y. On the choice of absolute or relative inequality measures. Milbank Q. 2010:88:616-22.

26. Kunst A, Mackenbach J. Measuring socioeconomic inequalities in health. Copenhagen: World Health Organization Regional Office for Europe; 2000.

27. Wacholder S. Binomial regression in GLIM: estimating risk ratios and risk differences. Am J Epidemiol. 1986;123:174-84

28. Barros AJD, Hirakata VN. Alternatives for logistic regression in cross-sectional studies: an empirical comparison of models that directly estimate the prevalence ratio. BMC Med. Res. Methodol. [Internet]. 2003;3:21. Available from: http://www.pubmedcentral.nih.gov/articlerender.fcgi?artid=521200\& tool=pmcentrez\&rendertype=abstract. Accessed 5 July 2016

29. Khang Y, Yun S, Lynch J. Monitoring trends in socioeconomic health inequalities: it matters how you measure. BMC Publ Heal. 2008;8:66. doi:10. 1186/1471-2458-8-66.

30. Spiegelman D, Hertzmark E. Easy SAS calculations for risk or prevalence ratios and differences. Am J Epidemiol. 2005;162:199-200.

31. Wagstaff A. Socioeconomic inequalities in child mortality: comparisons across nine developing countries. Bull. World Health Organ. [Internet]. 2000; 78:19-29. Available from: http://www.pubmedcentral.nih.gov/articlerender. fcgi?artid=2560599\&tool=pmcentrez\&rendertype=abstract

32. Zou G. A modified Poisson regression approach to prospective studies with binary data. Am J Epidemiol. 2004;159:702-6.

33. Kakwani N, Wagstaff A, van Doorslaer E. Socioeconomic inequalities in health: measurement, computation and statistical inference. J Econ. 1997:77:87-103.

34. Business Day Live. North West departments put under administratio. 2015;

35. Corruption Watch. The sickness in E Cape Health Department. 2016.

36. National Department of Health South Africa. Saving Mothers 2008-2010 Fifth Report on Confidential Enquiries into Maternal Deaths in South Africa [Internet]. 2012. Available from: http://www.doh.gov.za/docs/reports/2012/ savingmothersshort.pdf. Accessed 9 July 2016

37. Centre for Health Policy. Mapping maternal health research in low-middle income (LMIC) countries. Johannesburg, South Africa; 2014

38. National Department of Health SA. South African National AIDS Council. Clinical guidelines: PMTCT (Prevention of Mother-to-Child Transmission). 2010. 2010.

39. Goga A, Dinh T, Jackson D, SAPMTCTE study group. Evaluation of the effectiveness of the national prevention of mother-to-child transmission (PMTCT) programme measured at six weeks postpartum in South Africa. 2010.

40. Hoffman R, Black V, Technau K. Effects of highly active antiretroviral therapy duration and regimen on risk for mother-to-child transmission of HIV in Johannesburg, South Africa. J Acquir Immune Defic Syndr. 2010;54:35-41.

41. Okonji J, Zeh C, Weidle P. CD4, viral load response, and adherence among antiretroviral-naive breast-feeding women receiving triple antiretroviral prophylaxis for prevention of mother-to-child transmission of HIV in Kisumu. Kenya J Acquir Immune Defic Syndr. 2012;61:249-57.

42. Scorgie F, Blaauw D, Dooms T, Coovadia A, Black V. "I get hungry all the time": experiences of poverty and pregnancy in an urban healthcare setting in South Africa. Glob Heal. 2015;11:37. doi:10.1186/s12992-015-0122-z.

43. DSD SASSA and UNICEF. The South African Child Support Grant Impact Assessment: Evidence from a survey of children, adolescents and their households [Internet]. Pretoria; 2012. Available from: http://www.unicef.org/ southafrica/resources_10737.html. Accessed 11 Aug 2016

44. Murray M, Hunter B, Bisht R, Ensor T, Bick D. Demand-side financing measures to increase maternal health service utilisation and improve health outcomes: a systematic review of evidence from low- and middle-income countries. JBI Libr Syst Rev. 2012;10:4165-567.

45. UK Department for International Development and Bill and Melinda Gates Foundation. London Summit on Family Planning. 2012.

46. WHO. Strategic approaches to the prevention of HIV infection in infants: report of a WHO meeting, Morges, Switzerland, 20-22 March 2002. 2003 [Internet]. 2003. Available from: http://www.who.int/hiv/pub/mtct/en/ StrategicApproachesE.pdf. Accessed 10 July 2016
47. Jylha M. What is self-rated health and why does it predict mortality? Towards a unified conceptual model. Soc Sci Med. 2009;69:307-16.

48. Bailis D, Segall A, Chipperfield J. Two views of self-rated general health status. Soc Sci Med. 2003:56:203-17.

49. Dowd J, Todd M. Does self-reported health bias the measurement of health inequalities in U.S. Adults? evidence using anchoring vignettes from the health and retirement study. J Gerontol B Psychol Sci Soc Sci. 2011;66:478-89.

50. Mnyani C, Simango A, Murphy J, Chersich M, Mclntyre J. Patient factors to target for elimination of mother-to-child transmission of HIV. Glob Heal. 2014:10:36.

\section{Submit your next manuscript to BioMed Central and we will help you at every step:}

- We accept pre-submission inquiries

- Our selector tool helps you to find the most relevant journal

- We provide round the clock customer support

- Convenient online submission

- Thorough peer review

- Inclusion in PubMed and all major indexing services

- Maximum visibility for your research

Submit your manuscript at www.biomedcentral.com/submit
) Biomed Central 